\title{
PRODUÇÃO DE NIÓBIO A PARTIR DO BENEFICIAMENTO DE ROCHA FRESCA DA MINA BOA VISTA*
}

\author{
Joselito Dásio da Silva' \\ Daniel Gonçalves 2 \\ Pauliano Cruz Rufino ${ }^{3}$ \\ Elyssa Morinigo ${ }^{4}$ \\ Wellington Alves de Souza ${ }^{5}$
}

\begin{abstract}
Resumo
A Niobras é uma empresa do grupo China Molybdenum Internacional (CMOC), recentemente adquirida do grupo Anglo American, que extrai e beneficia minério de nióbio proveniente da Mina Boa Vista, situada no município de Catalão - GO, e transforma o concentrado de pirocloro em liga de ferro - nióbio em seu site situado em Ouvidor/GO, sendo este o produto final comercializado. A extração de minério na Mina Boa Vista iniciouse no ano de 2000 com o objetivo de alimentar a Planta de Concentração Boa Vista com minério oxidado, para manter o nível de produção de nióbio, uma vez que a antiga mina estava em processo de exaustão. Com a exaustão do minério oxidado prevista para 2016, em 2011 foi desenvolvido um projeto chamado BVFR (Boa Vista Fresh Rock) para produção de nióbio através da extração e beneficiamento de minério contido em rocha fresca. $O$ Projeto BVFR foi aprovado no início de 2012, concluído em outubro de 2014 e foram investidos mais de US\$350 milhões para sua implantação. O Projeto BVFR aumenta a vida útil da mina (Life Of Mine) e do negócio em 20 anos, triplica a produção de nióbio da Niobras e incrementa o EBTIDA em mais de $250 \%$ e gerou um aumento de mais de 400 empregos diretos (entre contratadas e próprios).
\end{abstract}

Palavras-chave: Nióbioplanta de concentração; processamento mineral; piroclorol

\section{NIOBIUM PRODUCTION FROM FRESH ROCK PROCESSING - BOA VISTA MINE CASE}

\section{Abstract}

Niobras is a China Molybdenum group company (CMOC International), recently acquired from Anglo American plc. It explores, exploits and concentrates niobium ore from Boa Vista Mine, located in Catalão, Goiás and turns it into Ferro-Niobium alloy, since the 70's. The operation of Boa Vista Mine has started up in 2000 to feed the concentration plant (called BV Plant) with weathered (oxidized) ore. Due to exhaustion of weathered ore forecasted to 2016, in 2011, the company developed a project called BVFR (Boa Vista Fresh Rock) to produce niobium from fresh rock niobium ore. The company approved BVFR project in 2012, erected in late 2014 with an investment of over US\$ 350 million. It has increased: life of mine in 20 years, production in three times, EBTIDA in over $250 \%$ and 400 jobs.

Keywords: Niobium; concentration plant; Pyrochlore ore; mineral process

1 Superior/Engenharia de Minas, Gerente de Produção, Produção, Niobras, Catalão, Goiás Brasil.

2 Superior/Engenharia Química, Coordenador de Produção, Produção, Niobras, Catalão, Goiás Brasil.

3 Superior/Engenharia de Minas, Coordenador de Produção, Produção, Niobras, Catalão, Goiás Brasil.

4 Superior/Engenharia de Minas, Engenheira de Processos, Produção, Niobras, Catalão, Goiás Brasil.

5 Superior/Engenharia de Minas, Engenheiro de Processos, Produção, Niobrás, Catalão, Goiás/Brasil. 


\section{NIOBRAS}

Desde o dia 30 de setembro de 2016 o grupo Anglo American concluiu a venda de seus negócios e operações de extração, processamento e comercialização de nióbio para entidades da China Molybdenum Co, Ltd (CMOC). A partir de então, a CMOC assumiu o controle e é a única responsável pelos negócios e operações de nióbio que anteriormente eram de propriedade da Anglo American.

\section{MATERIAIS E MÉTODOS}

O presente trabalho traz um compêndio de informações relativas à produção do concentrado de nióbio, realizada pela Niobrás, sua importância estratégica na produção da liga de ferro nióbio e apresenta a rota da planta BVFR (Boa Vista Fresh Rock) localizada em Ouvidor/GO e desenvolvida exclusivamente para processar a rocha não oxidada.

\section{NIÓBIO NO BRASIL E NO MUNDO}

O Brasil detém os maiores recursos e reservas minerais de nióbio, representado pelo minério denominado pirocloro, localizado nos municípios de Araxá e Tapira, no Estado de Minas Gerais, Ouvidor no Estado de Goiás e em São Gabriel da Cachoeira, no Estado do Amazonas.

O expressivo potencial das reservas brasileiras de pirocloro - cerca de $98 \%$ em termos mundiais - concede ao Brasil posição destacada no cenário internacional, pois além de deter tais recursos é o maior produtor do minério, inclusive sob a forma de concentrado e do principal produto metalúrgico, a liga de ferro - nióbio.

Detentor das principais reservas minerais, o Brasil responde pela quase totalidade da oferta da liga ferro - nióbio, metal e outros compostos. Duas empresas brasileiras respondem pela totalidade da produção mineral - Companhia Brasileira de Metalurgia e Mineração (CBMM), empresa pertencente ao Grupo Moreira Salles, localizada no município de Araxá, em Minas Gerais e a Niobras no município de Ouvidor em Goiás - ambas lavram o pirocloro.

O Brasil, por meio da produção da CBMM e da Niobras, responde por $93 \%$ da produção mundial, vindo a seguir, o Canadá (Niobec).

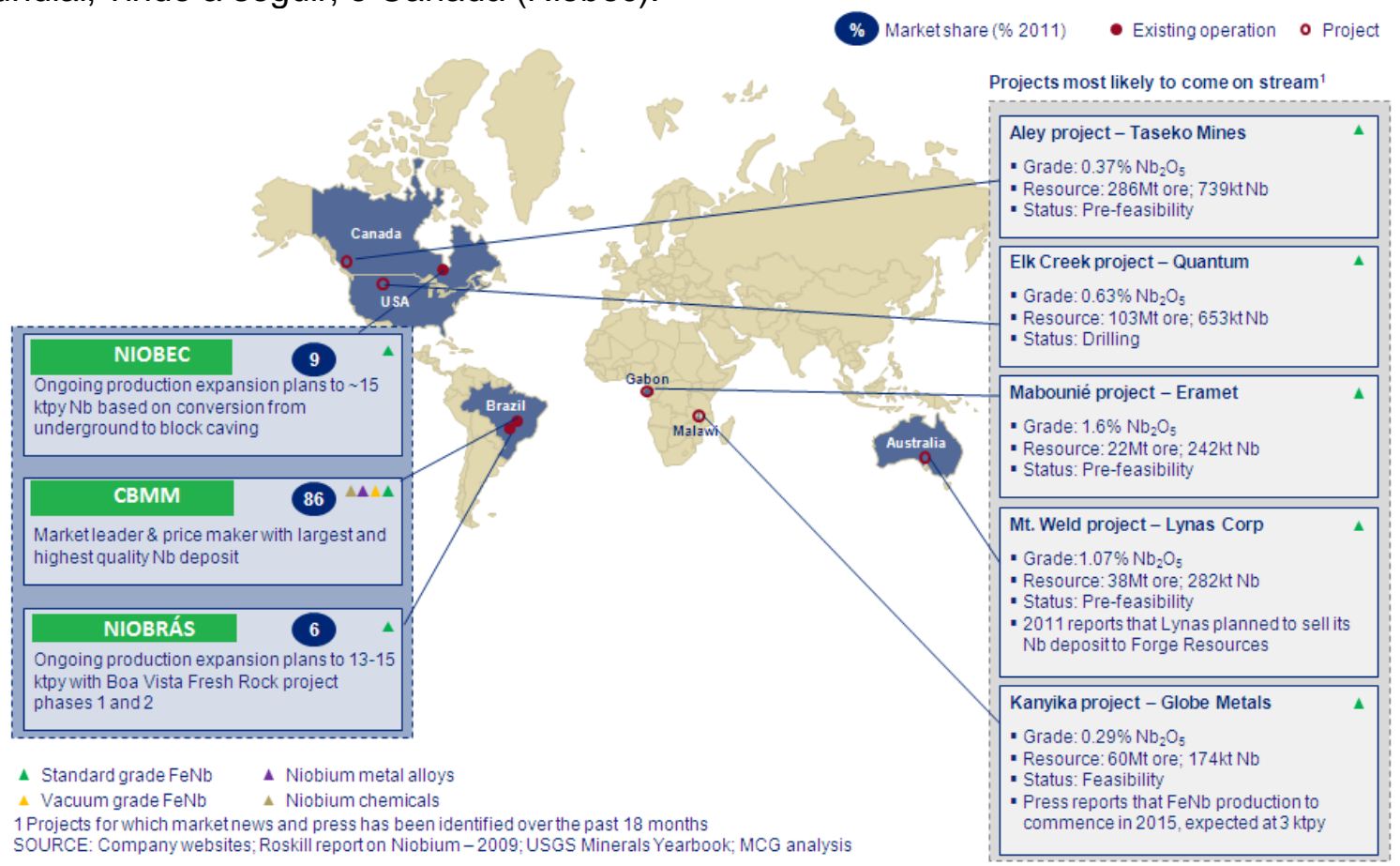

Figura 1. Reservas e Recursos de nióbio no mundo. 


\subsection{Aplicações}

O nióbio possui muitas utilidades e aplicações em diversos ramos econômicos: da siderurgia a setores intensivos em tecnologia. A aplicação mais comum do nióbio, ao contrário dos demais metais refratários, encontra uso principalmente na siderurgia e ocasionalmente no segmento não metalúrgico.

Existe um tipo de aço denominado (ARBL), aço de alta resistência e de baixa liga, que permite, por exemplo, a construção de estruturas de menor peso e custo reduzido. Para aumentar a resistência mecânica do aço, basta elevar o teor de carbono, contudo algumas propriedades do aço como soldabilidade, tenacidade e conformabilidade são prejudicadas neste caso.

No caso do nióbio as adições típicas são na faixa de 0,04\%, ou seja, para cada tonelada de aço, são acrescentadas 400 gramas de nióbio. A vantagem do nióbio em relação ao vanádio e ao titânio é que ele possui maior resistência; mas ao utilizá-lo em conjunto com os outros elementos, pode possibilitar ganhos de sinergia à liga, como a adição de nióbio e titânio, por exemplo, na liga de alta resistência, confere uma qualidade melhor do produto. Este aço especial pode ser utilizado na construção de oleodutos e gasodutos e plataformas para exploração de petróleo em águas profundas, construção naval. Na indústria automobilística, o aço microligado pode ser utilizado em tiras laminadas a quente, conferindo alta resistência mecânica, utilizados em chassis de caminhões e rodas de veículos, enquanto as tiras laminadas a frio são utilizadas na fabricação de automóveis.

O nióbio metálico é um dos metais que mais resistem à corrosão, principalmente em meios ácidos e metais alcalino fundidos. Também é utilizado em componentes de lâmpadas de alta intensidade para iluminação pública, associado ao metal tungstênio $(\mathrm{W})$, pois requer alta resistência mecânica, associadas à resistência corrosão pelo sódio $(\mathrm{Na})$.

Outra utilidade do nióbio metálico está na indústria aeroespacial, em propulsores e bocais de foguetes e está sempre presente na saia do motor Pratt \& Whitney F100, um gerador de alta potência usado nos caças F15 e F16. O metal nióbio pode ser utilizado também em ligas de nióbio-titânio, para uso em implantes cirúrgicos; em componentes de nióbio-titânio resistentes à ignição, usados por mineradoras, principalmente na extração de ouro; em lâminas de nióbio puro usadas na produção de diamantes sintéticos; em plataformas marítimas, com cabos anódicos de nióbio platinizados para proteção catódica (contra corrosão) e para alvos de evaporação usados na indústria eletrônica e nas lâminas de barbear.

O óxido de nióbio é utilizado na produção de cerâmicas finas como capacitores cerâmicos, lentes óticas, ferramentas, peças de motor e alguns elementos estruturais resistentes ao calor e a abrasão. A fabricação destes materiais requer óxido de nióbio de alta pureza. $\mathrm{O}$ óxido de nióbio com $99,9 \%$ de pureza é utilizado para a fabricação de peças cerâmicas, lentes óticas, condensadores e atuadores cerâmicos.

\section{PROCESSO DE PRODUÇÃO DE FERRO NIÓBIO}

\subsection{Planejamento e operação de mina}

Todas as operações de lavra são apoiadas em cuidadoso planejamento periodicamente revisado, visando antecipar quaisquer mudanças, quer sejam no tocante à geologia, na escala de produção, nas exigências do mercado, na frota de equipamentos, ou mesmo devido às condições climáticas. Como qualquer planejamento, o da Mina Boa Vista é subdividido em planejamentos de longo, médio e curto prazo.

O planejamento de longo prazo contempla a cava de exaustão e os planos de lavra para os períodos acima de 10 anos. No planejamento de médio prazo são detalhados os trabalhos para os períodos até 10 anos. No curto prazo são mantidos permanentemente atualizados os planos anuais para os próximos 3 anos. O primeiro desses planos (primeiro ano) é subdividido, por sua vez, em planos trimestrais e mensais. 
Os planejamentos são feitos com o apoio do software de mineração DATAMINE ${ }^{\mathrm{TM}}$.

Na Mina Boa Vista, o método de lavra utilizado é a céu aberto em bancadas com desmonte mecânico e por explosivos e transporte do minério por via rodoviária até a usina de beneficiamento. Este método emprega operações simples e de fácil aplicação, exigindo equipamentos de grande utilização em minerações deste porte.

$O$ desmonte / desagregação do minério é feito de forma mecânica pelo trator de esteiras. A rocha fresca é desmontada por meio de explosivos. A pá carregadeira e/ou escavadeira sobre esteiras fazem o carregamento nos caminhões que farão o transporte até a usina de beneficiamento da empresa em Ouvidor que fica $23,0 \mathrm{Km}$ da mina.

\subsection{Concentração na planta Boa Vista}

A Planta de Concentração Boa Vista foi construída na década de 70 para concentrar minério de nióbio (geralmente o pirocloro) intemperizado (oxidado).

$\mathrm{O}$ minério oxidado, com um teor médio de $1,2 \%$ de $\mathrm{Nb}_{2} \mathrm{O}_{5}$, lavrado é transportado até um circuito de britagem onde é fragmentado até que as partículas atinjam um tamanho máximo de 3 polegadas. O minério britado é estocado em um galpão de homogeneização para alimentar a planta de concentração a uma taxa de alimentação de 115t/h. A partir daí todo o processo é realizado à úmido.

No minério oxidado, o pirocloro está associado às partículas magnéticas (geralmente magnetita e em menor proporção na ilmenita) e na fração menor que $9 \mathrm{~mm}$. Com isso, a primeira fase de processamento consiste numa pré concentração, onde o minério é peneirado em um trommel com uma tela de $9 \mathrm{~mm}$ e em seguida em um separador magnético de média intensidade, onde o magnético segue para etapa seguinte e o não magnético é descartado como rejeito final. Este circuito enriquece o teor de $\mathrm{Nb}_{2} \mathrm{O}_{5}$ em $40 \%$ e remove aproximadamente $30 \%$, em termos de massa, dos contaminantes presentes.

O produto da pré concentração alimenta uma etapa de moagem composta de um moinho de barras e dois moinhos de bolas com o objetivo de reduzir o tamanho das partículas até atingir entre 15 e $20 \%$ retido em $0,1 \mathrm{~mm}(150 \#)$ que é a faixa de tamanho de liberação do pirocloro. Da etapa de moagem, a polpa é submetida a uma deslamagem, por meio de hidrociclones, como adequação para flotação.

A flotação consiste em três etapas. Duas flotações inversas e uma direta. Nas flotações inversas, os contaminantes são flotados, num primeiro estágio, são flotados os minerais de sílica (quartzo e micas) e no segundo estágio os minerais de carbonatos (calcita) e sulfatos (barita). Nas duas etapas o flotado constitui o rejeito final que é enviado para reservatórios de rejeito e o afundado é direcionado para etapa seguinte. Na terceira etapa consiste na flotação direta onde o pirocloro é flotado até obter um concentrado com teor de $\mathrm{Nb}_{2} \mathrm{O}_{5}$ acima de $50 \%$ e $\mathrm{SiO}_{2}$ abaixo de $3 \%$. Entre o segundo estágio da flotação reversa e a flotação direta, existe uma separação magnética (principalmente magnetita), onde o magnético é rejeito final.

A planta Boa Vista possui uma recuperação metalúrgica global de nióbio entre 30 e 50\% dependendo das características do minério alimentado. 
PILHA / ESCALPE / SEPARAÇĀO MAGNÉTICA / MOAGEM / CLA S SIFICAÇÄO / DE SLAMAGEM / FLOTAÇÄO / ESPES SAMENTO / BARRAGEM

(STOCKPILE / SCALP/MAGNETIC SEPARATION /MILLING / CLASSIFICATION / DESLAMING / FLOTATION / THICKENING / AAND TALINGS DAM)

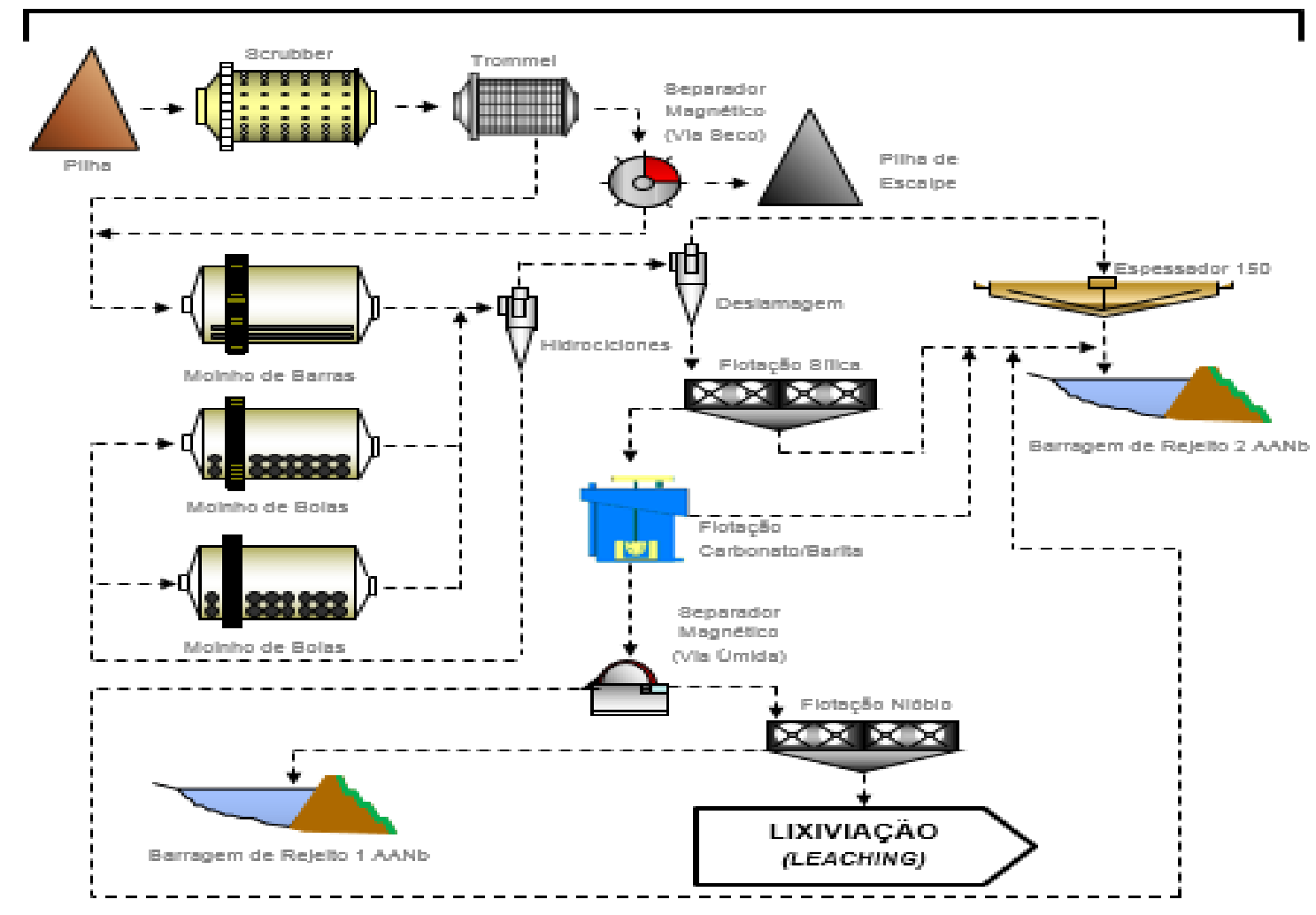

Fluxograma simplificado da Planta de Concentração BV

\subsection{Concentração na planta Tailings}

A planta Tailings iniciou suas operações em agosto de 2008, com o objetivo de recuperar $\mathrm{Nb}_{2} \mathrm{O}_{5}$ dos finos do rejeito (< 150\#) gerado nas plantas de concentração de fosfato da Copebras (também empresa do grupo China Molybdenum). Este rejeito alimenta a planta Tailings com um teor médio de $0,50 \%$ de $\mathrm{Nb}_{2} \mathrm{O}_{5}$.

As etapas principais do processo são: classificação por hidrociclones, peneiramento de alta frequência, moagem, deslamagem, flotação de sílica, separação magnética e flotação de nióbio. Estas etapas são similares, em termos de processo e operação, às etapas da Planta Boa Vista. Elas diferenciam em termos de capacidade de produção e a ausência da flotação de carbonatos na planta Tailings. O controle da operação da flotação é realizado por um sistema de controle especialista avançado, que toma decisões para alcance das metas de qualidade e produção sem a intervenção do operador.

O concentrado final é bombeado para planta de lixiviação, enquanto o rejeito desta etapa vai para os reservatórios de rejeito. A planta Tailings é responsável por $16 \%$ da produção de Nióbio da Niobras.

\subsection{Lixiviação e Calcinação}

Para que a qualidade da Liga FeNb seja assegurada, é necessária a remoção de alguns minerais que aumentam o nível de impurezas concentrado e afetam a qualidade da liga. Portanto, a lixiviação tem como objetivo adequar o teor de fósforo e enxofre às especificações definidas através da dissolução seletiva.

O concentrado proveniente da flotação de pirocloro alimenta dois filtros-tambor e é direcionado a um silo. As reações são realizadas por batelada, em reatores com agitadores, 
adicionando-se água e uma quantidade de soda cáustica e ácido clorídrico já calculados de acordo com os teores das impurezas contidas no concentrado produzido. A partir daí o concentrado é enviado para outro filtro onde o material cai num silo que alimenta o forno calcinador.

A calcinação é realizada em um forno cilíndrico rotativo e tem como objetivo a queima de alguma matéria orgânica contida no concentrado, a eliminação da umidade e da água de cristalização, garantindo as especificações que a metalurgia necessita para realizar as reações aluminotérmicas, além de garantir que estas não sejam explosivas por excesso de água.

Os gases e poeiras provenientes da queima são conduzidos a um ciclone (despoeirador), onde o overflow segue para um filtro de mangas e o underflow retorna como carga circulante.

O produto do forno passa por um resfriador rotativo que possui as paredes externas em contato com uma corrente de água e é descarregado por uma calha em um transportador pneumático, que abastece dois silos. Daí o material é embalado em big bags com capacidade de $1.850 \mathrm{Kg}$, e segue para Metalurgia.

$O$ produto da calcinação recebe o nome de concentrado final. Baseado nos teores de seus óxidos calcula-se a quantidade de alumínio e fluxos de calor para uma adequada redução aluminotérmica.

\subsection{Metalurgia}

A redução do $\mathrm{Nb}_{2} \mathrm{O}_{5}$ é realizada por aluminotermia e ocorre em bateladas em cadinhos. Um alimentador de cone duplo é utilizado para a alimentação do material nos cadinhos. Para cada reação é utilizada a massa de concentrado final equivalente a dois big bags, ou seja, $3.700 \mathrm{~kg}$ do produto. Também é utilizado na reação o óxido de ferro conhecido como blue dust ou hematita, fluorita, salitre do chile, pó de alumínio e cal fazendo com que a massa total no cadinho chegue a $5.500 \mathrm{~kg}$.

Desde a ignição até que seja completada a reação, decorre-se aproximadamente 20 minutos. Deixa-se vazar a escória (que representa um rejeito). A liga é então encaminhada para resfriamento dentro do próprio cadinho com areia.

\subsection{Britagem de ligas e expedição}

A liga FeNb obtida é britada e embalada conforme a especificação exigida pelos clientes. Seu transporte é realizado em caminhões até o porto de Santos onde ocorre o embarque marítimo, com o produto acondicionado em containers. Toda a produção é exportada e os principais mercados são: China, Japão, Europa, Índia, Emirados Árabes e Estados Unidos.

A composição química da liga FeNb obtida, atende às especificações internacionais da chamada Fe-Nb grau standard.

\section{O PROJETO BVFR}

O projeto BVFR iniciou-se em 2011, com o objetivo de capacitar a Niobras a produzir liga de ferro nióbio a partir da lavra e beneficiamento de minério de nióbio contido em rocha fresca. Para isso, foram construídos um circuito de britagem para redução das partículas a um tamanho máximo de $17 \mathrm{~mm}$, um pátio de homogeneização com duas pilhas formadas pelo método Chevron com capacidade para alimentar a planta de beneficiamento durante 28 dias e retomada com retomadora de ancinhos que realizam a homogeneização e uma planta de concentração com capacidade horária de 176t/h de alimentação e desenhada para obter uma recuperação metalúrgica de nióbio acima de $56 \%$ após o período de Rump up.

A primeira mudança em relação ao minério oxidado acontece na mina com a inclusão da etapa de perfuração e desmonte por explosivos. O minério oxidado era desmontado mecanicamente com a própria escavadeira que realizava o carregamento dos caminhões. 
Aproximadamente cinco anos de testes de laboratório, escala piloto e testes industriais utilizando a própria planta existente (Planta de Concentração Boa Vista) definiram as rotas de processo, os equipamentos a serem utilizados para a concentração do pirocloro a partir do minério de rocha fresca.

Em linhas gerais, o beneficiamento do minério de rocha fresca é similar ao minério oxidado. As diferenças estão nas perdas por etapas de concentração devido exclusivamente às características dos minérios (Ex: minério oxidado possui maior quantidade de lamas naturais que o minério de rocha fresca, presença de sulfetos na rocha fresca enquanto que no oxidado a presença é de sulfatos, energia de moagem para o minério oxidado menor que o minério de rocha fresca).

A planta de concentração BVFR inicia-se com a cominuição através de dois moinhos de bolas que reduzem o tamanho das partículas para uma faixa entre 15 e $20 \%$ da massa retida em $0,1 \mathrm{~mm}$ (150\#) tal como na planta Boa Vista, com a diferença de que na planta de concentração Boa vista são três moinhos: um de barras e dois de bolas.

O restante do processo é similar ao da planta Boa vista com as etapas de deslamagem, duas flotações inversas para remoção de minerais de sílica e carbonatos e sulfetos (pirita) e uma flotação direta do pirocloro.

\section{ARMAäENAMENTO / MOAGEM / CLA S SIFICAÇAO / DESLAMAGEM / SEPARAÇAO MAGNETICA / FLOTAÇAO / ESPESSAMENTO / BARRAGEM AANb}

(STORAGE SROS / MULING / CLASSUFICATION / DESLANUNG $/$ MAGNETIC SEPARATION / FLOTATION ITHJCRENWVG I AANB TARMVG DANS

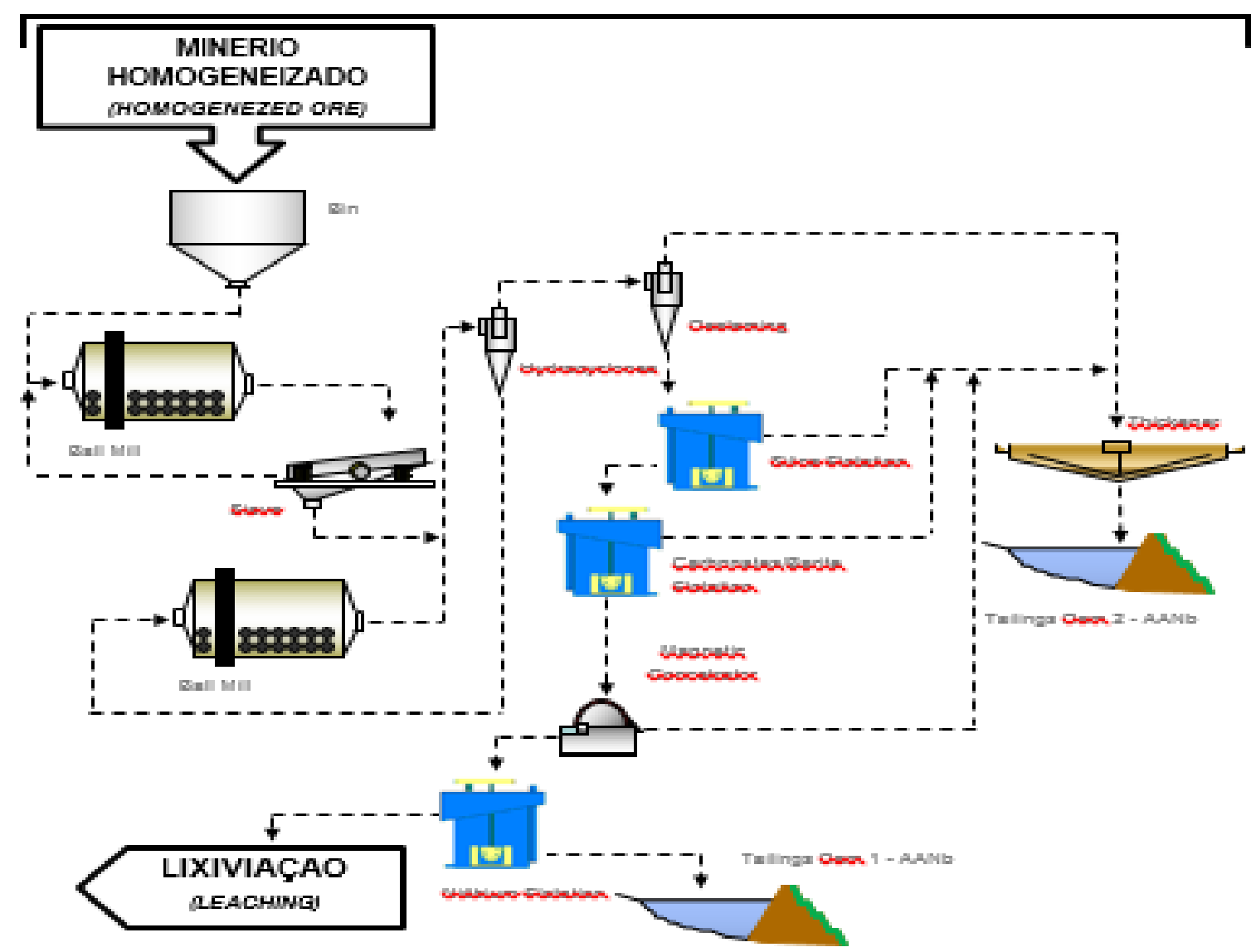

Fluxograma simplificado da Planta BVFR 


\section{RESULTADOS}

A implantação do projeto BVFR permitiu a continuidade do negócio e um expressivo acréscimo de produção, gerando mais valor ao ativo. O gráfico abaixo mostra, em termos percentuais, o acréscimo de produção a partir do atingimento da capacidade nominal da Planta BVFR.

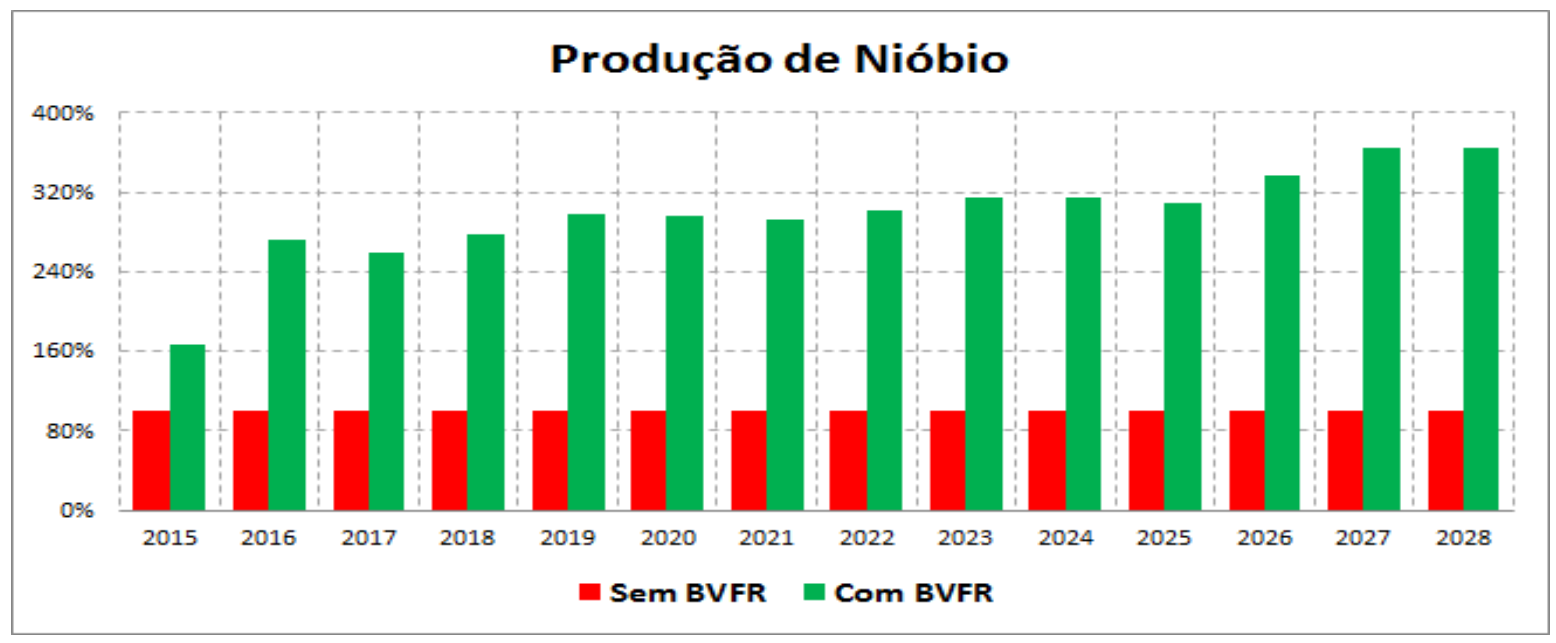

Produção de nióbio

Com os resultados acima expostos apresentam-se os seguintes valores de EBITDA:

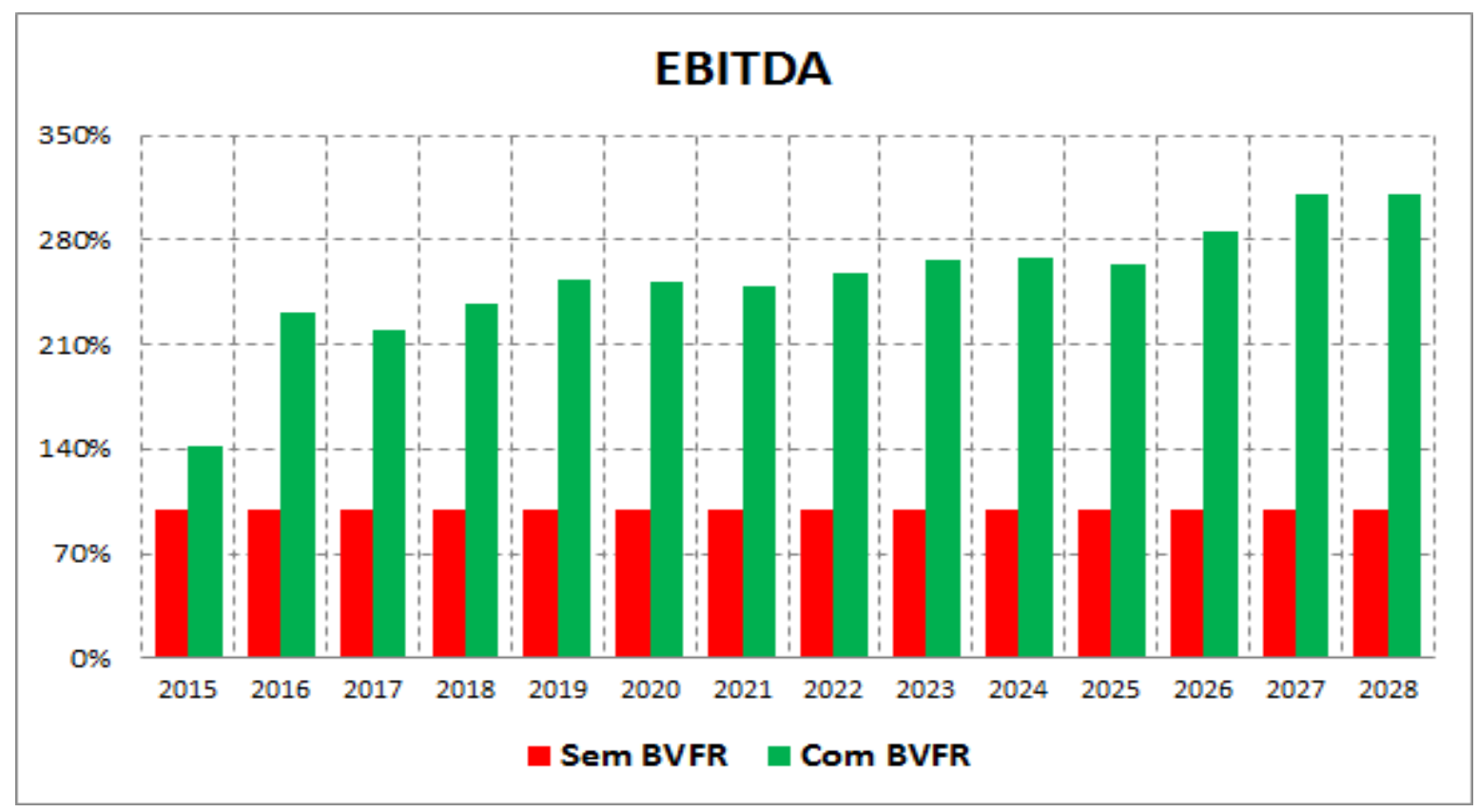

EBITDA 


\section{CONCLUSÃO}

Destarte é destacado que o projeto BVFR aprovado no início de 2012 e concluído em outubro de 2014, no qual foram investidos mais de US\$ 350 milhões para sua implantação, atingiu excelentes resultados como demonstrado, através de uma planta que apresenta excelência na concentração do nióbio extraído a partir da rocha fresca.

O Projeto BVFR aumentou a vida útil da mina (Life Of Mine) e do negócio em 20 anos, triplicando a produção de nióbio da Niobrás e incrementando o EBTIDA em mais de $250 \%$ além de permitir um aumento de mais de 400 empregos diretos (entre colaboradores terceirizados e próprios)

\section{REFERÊNCIAS}

Todos os dados apresentados foram extraídos de arquivos técnicos internos da Niobrás. 